\title{
The perpetual dance of continents
}

\section{Supercontinent: Ten Billion Years in the Life of our Planet \\ by Ted Nield \\ Granta Books/Harvard University Press: \\ 2007. 352/304 pp. $€ 18.99 / \$ 29.95$}

\section{David Oldroyd}

As a geologist turned science journalist, editor and provocative blogger, Ted Nield has a complex view of life and science. His skills as a writer successfully convey in Supercontinent the recent exciting work in grand-scale geoscience to a wide scientific audience.

Nield's task is immense: to give an intelligible account of Earth's history, beyond the familiar story of wandering continents, drift and the simpler ideas of plate tectonics. He tells us what is thought to have happened way before Alfred Wegener's Pangaea (pictured here), following the trail of analogous earlier 'supercontinental' land masses: Pannotia, Rodinia, Atlantica, Columbia, Nena and Ur - the last probably appearing fairly soon after Earth's formation. To embrace a span of 10 billion years, Nield also envisages a whole succession of future supercontinents. Indeed, the next assemblage has already been named: Novopangaea.

Geoscientists have long been reconstructing continents, and their results are wonderfully displayed at various websites (such as www.scotese. com). Nield wants to help readers understand just how such reconstructions have been produced and how more recent work is extending reconstructions into the future as well as the past. He links the perpetual 'quadrille' of the continents to plate movements, climatic and atmospheric changes, and life's causal role in the changes. Everything is driven by the great convection currents within Earth's mantle.

Thus Supercontinent recounts geologists' debates about the 'introversion' and 'extroversion' of continents and describes the intricate geochemical and geomagnetic work that underpins their endeavours. Fearlessly, Nield plunges into the complex problems of the role of ophiolites, pieces of oceanic plate thrust onto the edge of continental plates, in revealing the histories of continents and oceans. He describes what he calls 'Rust World', when banded ironstone formations emerged 3.5 to 1.5 billion years ago, owing to the production of oxygen in the atmosphere by simple photosynthesizing life-forms.

There followed the age of stromatolites, dubbed here 'Lasagne World'. Then a period of cooling, when organisms sapped the atmosphere of the greenhouse gas carbon dioxide, and sunlight reaching Earth was reduced by dust from volcanic eruptions accompanying the break-up of Rodinia. So came 'Iceworld' or 'Snowball Earth'. This world is thought to have had several episodes during the period 710-580 million years ago, the climatic swings being due to the opposing effects of outbursts of volcanic gases and the sequestration of carbon dioxide by living organisms. The huge swings supposedly ceased when Rodinia fractured and landmasses were no longer mostly located near the Equator. The evolution of 'modern' life-forms quickly followed.

All this is admirably described. The attempted reconstructions of past and future continents and oceans is a major field of

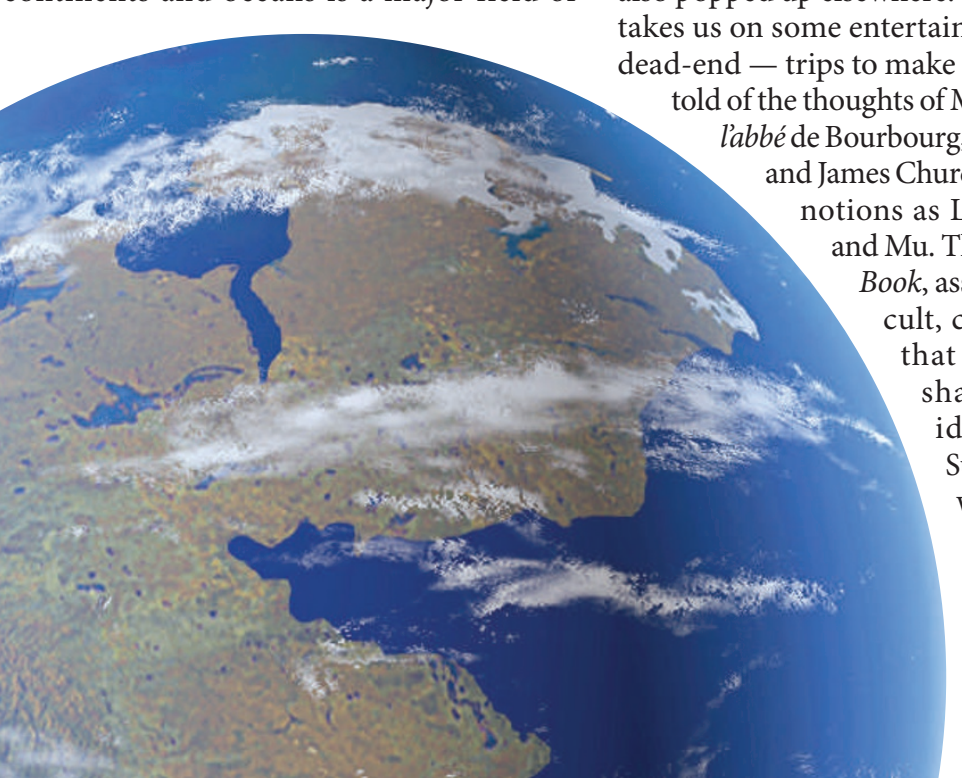

activity in contemporary geoscience. To handle it without oversimplification or getting lost in a maze of detail is no small accomplishment. I know of no other attempt to reduce the complexities of the relevant primary literature to the confines of a single popular-science book. However, one major element is glossed over: why do supercontinents form? They are thought to break up owing to radiogenic heat trapped beneath. But why aren't there perpetual random associations of land masses going on all over the globe? Why should there be a series of continental coalescences? The 'introversion' and 'extroversion' models partly address these questions, but undoubtedly there is much more to be said about them.

Nield rightly deems it important for the public to grasp the outlines of current (geo)scientific thinking and debate. Presumably to sweeten the pill, he brings key people into the story to good effect, incorporating contributions from the likes of Lord Kelvin, Wegener, John Joly, Tuzo Wilson, Janet Watson, John Sutton, Paul Hoffman and Christopher Scotese. The idea of supercontinents (or other continents) has also popped up elsewhere. So Supercontinent takes us on some entertaining - if, frankly, ead-end - trips to make this point. We are of the thoughts of Madame Blavatsky, bé de Bourbourg, Ignatius Donnelly d James Churchward about such ok, associated with a US ult, contains passages that by chance foreshadowed modern ideas on Rodinia. Such matters are not worth much attention, but I applaud Nield's brief swipe at American creationists.

Supercontinent warrants a special place in airport bookshops to stimulate travellers to contemplate the impermanence of the continents and seas they are flying over.

David Oldroyd is honorary visiting professor of history and philosophy of science at

University of New South Wales, Sydney, New South Wales 2052,

Australia, and author of Thinking About the Earth: A History of Ideas in Geology and Earth Cycles: A Historical Perspective. 